\title{
PENGARUH KEMAJUAN TEKNOLOGI INTERNET TERHADAP RENDAHNYA MINAT BELAJAR SISWA SMP NEGERI 4 RUTENG MANGGARAI BARAT
}

\author{
Florianus Gandur, Damianus Tola, Stefanus H. Gusti Ma \\ e-mail: floriigandur@gmail.com,datobela28@gmail.com, ephentino@gmail.com \\ Program Studi Pendidikan Ekonomi, FKIP, Universitas Flores
}

\begin{abstract}
Abstrak
Tujuan penelitian ini adalah untuk mengetahui kemajuan teknologi internet berpengaruh terhadap rendahnya minat belajar siswa pada SMP Negeri 4 Ruteng Manggarai Barat.Jenis penelitian yang digunakan adalah penelitian asosiatif dengan teknik pengumpulan data menggunakan kuesioner. Populasi dalam penelitian ini adalah siswa SMP Negeri 4 Ruteng. Dengan sampel sebanyak 25 responden.Analisis data dilakukan dengan menggunakan analisis regresi sederhana. Dari hasil uji t menunjukan bahwa variabel kemajuan teknologi internet dengan variabel rendahnya minat belajar siswa memiliki hubungan yang positif dan signifikan.. Hal tersebut di lihat dari nilai $t_{\text {hitung }}>t_{\text {tabel }}$ dengan tingkat signifikan $0,05,(4,103>1,713$, sig. $0,00<$ 0,05). Hasil uji koefisien determinasi $\left(\mathrm{R}^{2}\right)$ sebesar 0,821 atau $82,1 \%$ menunjukan bahwa besar sumbangan variabel kemajuan teknologi internet terhadap rendahnya minat belajar siswa pada SMP Negeri 4 Ruteng Manggarai Barat.

Kata Kunci: Teknologi, Siswa, Internet, Belajar, Minat
\end{abstract}

Abstract

The aim of this research is to know the effect of internet technology advances to the lack of student learning interest on students of SMP Negeri 4 Ruteng, Manggrai Barat. The research types used is associatif research. Meanwhile, the technique for gathering data is questionnaire. The population for this research are students of SMP Negeri 4 Ruteng. The sample of this study are 25 respondent. Data analysis used is a simple regretion. Based on the result of test shows that the variable of internet technology advance and the variable of the lack of students learning interest have positive relation and significant. It can be seen through $t_{\text {hitung }}>t_{\text {tabel }}$ with the level of significant $0,05,(4,103>1,713$, sig. $0,00<0,05)$. The result of coofecient determination test $\left(R^{2}\right)$ is 0,821 or $82,1 \%$ shows that it has big effect on internet technology advances to the lack of students learning interest on students of SMP Negeri 4Ruteng, Manggarai Barat.

Keywords: technology, students, internet, learning interest 


\section{A. PENDAhuluan}

Kehadiran teknologi internet dalam bidang pendidikan tentu memberikan banyak kemudahan, serta sebagai cara baru dalam melakukan aktivitas manusia. Manusia juga sudah menikmati banyak manfaat yang dibawa oleh inovasi-inovasi teknologi yang telah dihasilkan dalam dekade terakhir ini oleh Muhamad (2014).Teknologi selalu berkembang dan mengalami kemajuan sehingga semakin memudahkan manusia untuk beraktivitas.

Jejaring sosial merupakan situs dimana setiap orang bisa membuat webpribadi, kemudian terhubung dengan teman-teman untuk berbagi informasi dan berkomunikasi. Jejaring sosial terpopuler di antaranya Facebook, Twitter, Instagram,Telegram, Line, Whatsaap Jejarig ini mengajak siapa saja yang tertarik untuk berpartisipasi dengan memberi kontribusi dan feedback secara terbuka, memberi komentar, serta membagi informasi dalam waktu yang cepat dan tak terbatas. Sebagian besar pengguna jejaring sosial adalah dari kalangan remaja pada usia sekolah. Dengan berbagai fitur interaksi sosial yang ditawarkan oleh berbagai media sosial tersebut, para remaja kemudian tenggelam dalam keasyikan di dunia tanpa batas waktu.Para remaja lebih cenderung melakukan kegiatan yang kurang bermanfaat dalam mengakses situs jejaring sosial tersebut sehingga menyebabkan lupa waktu untuk belajar bagi siswa serta berpengaruh terhadap penurunan prestasi belajar siswa di sekolah.

Sekolah membekali peserta didik dengan pengetahuan keterampilan dan sikap agar berkompeten dalam bidang pendidikan.Sarana mengakses informasi yang ada tergolong masih kurang, seperti ketersediaan buku yang masih terbatas jumlahnya.Selain itu fasilitas komputer dan internet masih sangat terbatas, sehingga masih banyak siswa yang belum dapat memanfaatkan fasilitas yang ada di sekolah secara maksimal sebagai sumber belajar.Sesuai dengan kondisi yang ada banyak siswa yang belum sadar dan pekah menggunakan teknologi internet untuk aktivitas-aktivitas yang positif.Siswa hanya mempergunakan waktu untuk kegiatan-kegiatan yang dapat merugikan dirinya seperti mengobrol tentang hal-hal yang negatif, bermain, dan bermalas-malasan. Waktu banyak disalahgunakan, seharusnya dapat digunakan untuk aktivitas-aktivitas yang akan mendapatkan manfaat pada dirinya seperti belajar mendonwload materi-materi yang berkaitan matapelajaran.Keterlenaan dalam menggunakan media internet, ini berdampak pada hilangnya fokus saat kegiatan belajar mengajar di kelas dan juga munculnya rasa malas untuk tidak memperhatikan materi yang diajarkan secara serius.Sarana mengakses informasi yang ada tergolong masih kurang, seperti ketersediaan buku yang masih terbatas jumlahnya.Selain itu fasilitas komputer dan internet masih sangat terbatas, sehingga masih banyak siswa yang belum dapat memanfaatkan fasilitas yang ada di sekolah secara maksimal sebagai sumber belajar.

Salah satu aktivitas belajar yang dapat dimanfaatkan siswa untuk dapat mengembangkan potensi dirinya adalah sekolah, aktivitas yang dapat dilakukan siswa di sekolah seperti membaca, menulis, bertanya, dan mengeluarkan pendapat di SMP Negeri 4 Ruteng Manggarai Barat, Sekolah menengah pertama (SMP) Negeri 4 Ruteng Manggarai Barat membekali peserta didik dengan pengetahuan keterampilan dan sikap agar berkompeten dalam bidang pendidikan.

Berdasarkan masalah penulis terdorong untuk melakukan pengkajian tentang bagaiamana pengetahuan siswa tentang kemajuan teknologi internet pada SMP Negeri 4 Ruteng Manggarai Baratdan bagaiaman penggunaan teknologi internet terhadap rendanya minat belajar siswa SMP Negeri 4 Ruteng Manggarai Barat adapun tujuan yang diangkat dalam penelitian yakni:

1. Untuk mengetahui kemampuan siswa tentang kemajuan teknologi internet.

2. Untuk mengetahui minta belajar siswa terhadap kemajuan teknologi internet SMP Negeri 4 Ruteng Manggarai Barat.

Teknologi dibuatatas dasar ilmu pengetahuan dengan tujuan untuk mempermuda pekerjaan manusia, kemajuan teknologi sesuatu yang tidak bisa kita hindari dalam kehidupan saat ini, karena kemajuan teknologi akan berjalan sesuai dengan kemajuan ilmu pengetahuan. Adapun teori pendukung dalam kemajuan teknologi Naisbit (2002) mengutip pengertian dari teknologi dari Random House Dictionary, mengatakan bahwa teknologi merupakan sebuah benda dan juga objek serta bahan dan wujud yang berbeda dibandingkan dengan manusia dan juga disampaikan oleh Miarso (2007) mengungkapkan bahwa teknologi merupakan suatu bentuk proses yang meningkatkan nilai tambah.Teknologi adalah sebuah metode praktis yang digunakan untuk menciptakan sesuatu yang berguna dan bisa digunakan secara berulang kali.

Teknologi diciptakan oleh manusia yang berhubungan dengan kegiatan praktis yang dilakukan manusai sehari-hari. Castells (2011) menyebutkan bahwa teknologi merupakan suatu kumpulan alat, autaran dan juga prosedur yang 
merupakan penerapan dari sebuah pengetahuan ilmiah terhadap sebuah pekerjaan tertentu dalam suatu kondisi yang dapat memungkinkan terjadinya pengulangan, adapun teori yang diungkap oleh Risky(2019)jaringan komputer diciptakan yang mampu berkomunikasi langsung antar kumputer, perhitungan dan kumunikasi melibatkan computer di jaman dulu yang dilakukan secara manual yang manusia dijadikan pengganti kumnikasinya.sangat besar yang terdiri dari jutaan perangkat komputer yang terhubung melalui suatu protokol untuk pertukaran informasi atntara komputer.

Internet adalah jaringan komputer diseluruh dunia yang berfungsi untuksarana komunikasi dan pencarian informasi yang menggunakan infrastruktur telekomunikasi yang telah ada (saluran telepon, satelit dll).Miskahudi (2017) Internet saat ini sudah menjadi bagian kehidupan sehari-hari, sehingga hampir setiap orang, bahkan yang ada di daerah pedesaan atau pelosok pun dapat mengakses internet, itulah bukti bahwa internet sekarang ini telah menjadi pokok kehidupan.Dunia seakan-akan tidak memiliki batas ruang dan waktu, sehingga sangat mudah dijelajahi.Siapapun dapat dengan mudah berkenalan dan berinteraksi, bahkan menjalin hubungan yang akrab dengan individu lainnya dari berbagai belahan dunia manapun, tanpa kendala.

Hal inilah yang mampu ditawarkan internet, sebagai dunia maya yang mampu mengkoneksikan dengan begitu mudah.Sidharta dalam (Suban 2018) memberikan definisi yang sangat luas terhadap internet. Internet adalah forum global pertama dan perpustakaan global pertama dimana setiap pemakai dapat berpartisipasi dalam segala waktu.Karena internet merupakan perpustakaan global, maka pemakai dapat memanfaatkanya sebagai media pembelajaran.Minat belajar adalah perhatian rasa suka.belajar berkaitan dengan aspek psikologis seseorang yang menapakan diri dalam beberapa gejalah seperti gairah, keinginan.berkaitan dengan perasaan suka atau senang dari seseorang terhadap sesuatu objek. Hal ini didukung juga oleh Slameto dalam (Arisanti dan Subhan 2018) yang menyatakan bahwa minat sebagai suatu rasa lebih suka dan rasa keterikatan pada suatu aktivitas, tanpa ada yang menyuruh. Minat pada dasarnya adalah penerimaan akan suatu hubungan antara diri sendiri dengan sesuatu di luar diri.

Slameto dalam (Arisanti, dan Subhan 2008) mengungkapkan bahwa suatu minat dapat diekspresikan melalui suatu hal dari pada hal lainnya.Minat belajar adalah salah satu bentuk keaktifan seseorang yang mendorong unruk melakukan serangkaian kegiatan jiwa dan raga untuk memperoleh suatu perubahan tinhkah laku sebagai hasil dari pengalaman individu dalam ineraksi dalam lingkungannya yang menyangkut kognitif, afektif, dan psikomotorik.Dengan memperhatikan pengertian minat belajar tersebut, maka semakin kuatlah kesimpulan tentang anggapan bahwa minat belajar adalah suatu hal yang abstrak (tidak bisa dilihat secara langsung dengan mata kepala), namun dengan memperhatikan dari aktivitas serta hal-hal lain yang dilakukan oleh seseorang.

Faktor-faktor yang mempengaruhi rendahnya minat belajar siswa merupakan sesuatu proses pendewasaan berfikir bagi peserta didik untuk dapat lebih meningkatkan minat belajarnya secara lebih mandiri dan tidak bergantung kepada orang lain. Minat tidak mudah terpengaruh oleh keadaan yang dapat mengurangi dalam belajar, juga diakatakan oleh Nasir (2017) proses pembelajaran berbagai faktor yang mempengaruhi rendahnya minat belajar siswa antara lain faktor internal dan faktor eksternal.

Faktor Internal (Kondisi siswa) Ketika siswa sedang merasakan suasana hati yang tidak menyenangkan karena berbagai perasaan negatif (sedih, tertekan, kecewa, atau marah, sakit) tentu saja ia akan merasakan kesulitan untuk berkonsentrasi dalam belajar. Sedangkan Faktor Eksternal Guru sebagaipelaku pengajaran menjadi faktor penentu berlangsungnya kegiatan pembelajaran yang kondusif. Bagaimana suasana pembelajaran sangat tergantung pada kemampuan dan kondisi guru (penguasaan materi, kesehatan, waktu dan kesibukan, beban/masalah individu dan keluarga, suasana hati dan emosi, motivasi dan pengalaman).

\section{B. METODE PENELITIAN}

Berdasarkan permasalahan yang diangkat penelitian ini, meneliti siswa kelas VIII SMP Negeri 4 RutengManggarai Barat.Sampel dalam penelitian ini sebanyak 25 orang responden. Dengan teknik pengambilan sampel menggunakan nonprobability sampling menurut sugiyono (2010) teknik sampling jenuh adalah teknik pengambil sampel bila semua anggota populasi digunakan sebagai sampel.

Teknik pengumpulan data yang dilakukan dengan cara memberi kuesioner kepada responden untuk dijawab, dengan skala yang digunakan peneliti adalah skala likert. Teknik analisis data yang digunakan adalahanalisis regresi liner sederhana untuk mempermuda pengolahan data penelitian ini 
digunakan aplikasi SPSS versi 16. Selanjutnya data diolah untuk mengukur penggunaan teknologi inetrnet terhadap rendahnya minat belajar siswa SMP Negeri 4 RutengManggarai Barat. Analisis regresi linier sederhana yang dikemukakan oleh Pratama, (2015) dengan rumus sbb:

$$
\begin{aligned}
& Y=a+b 1 X+e \\
& \text { Keterangan } \\
& \mathrm{Y}=\text { rendahnya minat belajar }
\end{aligned}
$$

\section{HASILDANPEMBAHASAN}

\section{Hasil uji validitas}

Uji validitas dilakukan untuk melihat valid tidaknya masing-masing instrument yang digunakan dalam variabel penelitian. Sesuai dengan hasil analisa data primer maka, masing- masing instrumen yang digunakan dalam penelitian memiliki hasil uji dengan melihat hasil $\mathrm{R}_{\text {hitung }}$ yang dibandingkan dengan $\mathrm{R}_{\text {tabel }}$, dimana $R_{\text {tabel }}$ yang diperoleh melalui $\mathrm{df}$ $($ degree of freedom $)=\mathrm{n}-2(\operatorname{sig} .5 \%, \mathrm{n}=$ jumlah sampel). Adapun nilai $\mathrm{R}_{\text {tabel }}$ dengan sampel $(\mathrm{n}=25), \mathrm{df}=(25-2)=23$ pada alpha $5 \%$ adalah 0,396 . Pengujian validitas dilakukan dengan menggunakan program SPSS versi 16.dengan kriteria sebagai berikut:

$$
\text { a. Bila } \mathrm{R}_{\text {hitung }}>\mathrm{R}_{\text {tabel }} \text { makan }
$$
pernyataan tersebut valid.

b. Bila $\quad \mathrm{R}_{\text {hitung }}<\mathrm{R}_{\text {tabel }}$ maka

\begin{tabular}{|c|c|c|c|c|}
\hline No & Indikator & $\mathbf{R}$ hitung & $\mathbf{R}$ tabel & Keterangan \\
\hline \multirow[t]{11}{*}{1} & Variabel kemajuanteknologi & & & \multirow{11}{*}{ VALID } \\
\hline & - Indikator 1 & 719 & 0,396 & \\
\hline & - Indikator 2 & 457 & 0,396 & \\
\hline & - Indikator 3 & 538 & 0,396 & \\
\hline & - Indikator 4 & 524 & 0,396 & \\
\hline & - Indikator 5 & 586 & 0,396 & \\
\hline & - Indikator 6 & 658 & 0,396 & \\
\hline & - Indikator 7 & 644 & 0,396 & \\
\hline & - Indikator 8 & 488 & 0,396 & \\
\hline & - Indikator 9 & 664 & 0,396 & \\
\hline & - Indikator 10 & 471 & 0,396 & \\
\hline \multirow[t]{16}{*}{2} & $\begin{array}{l}\text { Variabel rendahnya minat belajar } \\
\text { siswa }\end{array}$ & R hitung & $\mathbf{R}$ tabel & Keterangan \\
\hline & - Indikator 1 & 709 & 0,396 & \multirow{15}{*}{ VALID } \\
\hline & - Indikator 2 & 441 & 0,396 & \\
\hline & - Indikator 3 & 399 & 0,396 & \\
\hline & - Indikator 4 & 430 & 0,396 & \\
\hline & - Indikator 5 & 495 & 0,396 & \\
\hline & - Indikator 6 & 575 & 0,396 & \\
\hline & - Indikator 7 & 670 & 0,396 & \\
\hline & - Indikator 8 & 804 & 0,396 & \\
\hline & - Indikator 9 & 533 & 0,396 & \\
\hline & - Indikator 10 & 436 & 0,396 & \\
\hline & - Indikator 11 & 503 & 0,396 & \\
\hline & - Indikator 12 & 453 & 0,396 & \\
\hline & - Indikator 13 & 703 & 0,396 & \\
\hline & - $\quad$ Indikator 14 & 438 & 0,396 & \\
\hline & - Indikator 15 & 725 & 0,396 & \\
\hline
\end{tabular}
pernyataan tersebut tidak valid Berdasarkan hal tersebut, berikut ini adalah rincian tabel uji validitas untuk setiap variabel yang digunakan dalam penelitian. Uji validitas variabel kemajuan teknologi internet (X) dan rendahnya minat belajar (Y) dapat dilihat pada tabel berikut:

Tabel 1. Hasil uji validitas

Sumber: Olahan Data Primer 
Berdasarkan tabel diatas menjelaskanbutir pertanyaan kuesioner yang disebarkan pada siswa SMP Negeri 4 Ruteng Manggarai Barat dengan variabel kemajuan teknologi internet dan rendahnya minat belajar siswa dinyatakan valid dan layak untuk diolahmenggunakan alat analisis regresi linier Sederhana.
Uji reliabilitas untuk mengetahui adanya konsisten penggunan alat ukur. Reliabilitas variabel ditentukan berdasarkan nilai alpha cronbach, apabila nilai alpha lebih besar dari 0,60 maka dikatakan variabel tersebut reliabel atau dapat diandalkan.Hasil pengujian reliablitas dalam penelitian ini ditunjukan pada tabel 2 dibawah ini:

\section{Hasil Uji Reliabilitas}

Tabel 2. Hasil Uji Reliabilitas

\begin{tabular}{|l|l|l|l|l|}
\hline No & Variabel & $\begin{array}{c}\text { Nilai } \\
\text { Cronbach } \\
\text { Alpha }\end{array}$ & Kriteria & Keterangan \\
\hline 1 & kemajuan teknologi internet (X) & 0,786 & 0,60 & Reliabel \\
\hline 2 & rendahnya minat belajar siswa (Y) & 0,837 & 0,60 & Reliabel \\
\hline
\end{tabular}
Sumber:Olahan Data Primer

Berdasarkan tabel diatas dijelaskan nilai Cronbach's Alpha dari variable kemajuan teknologi internet sebesar 0,786> 0,60 dikategorikan realibel, dan variabel rendahnya minat belajar siswa sebesar 0,837> 0,60 dikategorikan realibel.Maka dapat dinyatakan bahwa setiap variabel yang diteliti inyatakan reliable dengan nilai Cronbach's Alpha lebih besar dari 0,60.

\section{Analisi Regresi Linier Sederhana}

Penelitian bertujuan untuk mengetahui besarnya variabel bebaskemajuan teknologi internet (independen) yang mempengaruhi variabel terikat rendahnya minat belajar siswa (dependen) untuk mengetahui data yang suda diolah perhatikan tabel 3 dibawah ini.

\section{Coefficients $^{\mathbf{a}}$}

\section{Tabel 3. Hasil Regresi Linear Sederhana}

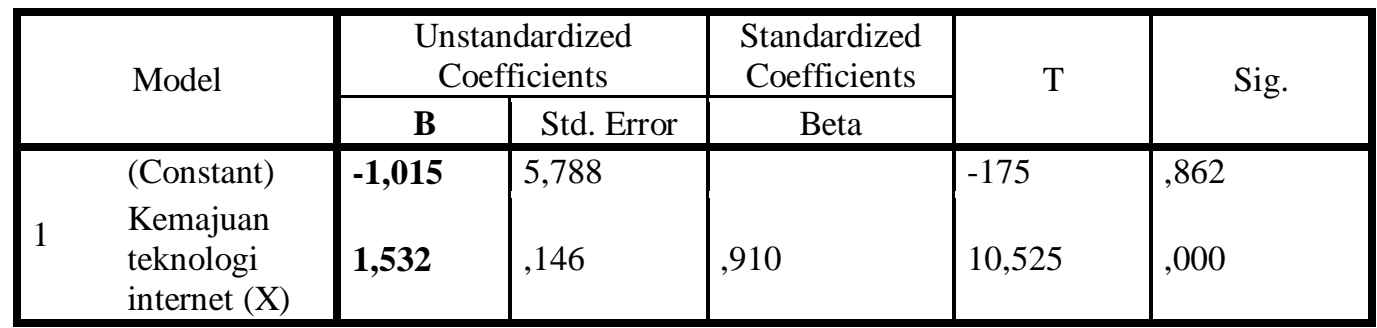

Sumber: Olahan data primer

Berdasarkan tabel diatas diketahui pada kolom kedua (Unstandardized Coefficients) bagian B diperoleh nilai $\mathrm{b}_{1}$ Kemajuan teknologi internet sebesar 1,532, dan nilai konstanta sebesar -1,015, maka diperoleh persamaan regresi linear sederhana sebagai berikut:

$$
\begin{gathered}
\square=\square+\square, \square+\square \\
\mathbf{Y = ~ - 1 , 0 1 5 + 1 , 5 3 2 + e}
\end{gathered}
$$

Bila nilai konstanta sebesar $-1,015$ menunjukkan variabel kemajuan teknologi sebesar 1,532 dengan probabilitas 0,000 (p < 0,05) dengan R2 sebesar 82,1 persen menandakan variabel kemajuan teknologi signifikan.

Uji $\mathrm{t}$ digunakan untuk mengetahui masing-masing variabel dependen yaitu variabel kemajuan teknologi internet terhadap rendahnya minat belajar siswa dengan cara membandingkan nilai signifikannya dengan $\alpha$. Untuk mengetahui $\mathrm{t}_{\text {tabel }}$ digunakan rumus sebagai berikut:

Rumus: $\mathrm{df}=\mathrm{n}-\mathrm{k}-1$

$$
\mathrm{df}=25-1-1=23
$$

Nilai $t_{\text {tabel }}$ dari $23=1,713$

Secara lengkap hasil uji t dapat disajikan pada tabel 4 berikut: 
Coefficients $^{\mathbf{a}}$

Tabel 4 Hasil Uji Statistik T

\begin{tabular}{|c|l|l|l|l|l|}
\hline \multirow{2}{*}{ Model } & \multicolumn{2}{|c|}{$\begin{array}{c}\text { Unstandardized } \\
\text { Coefficients }\end{array}$} & $\begin{array}{c}\text { Standardized } \\
\text { Coefficients }\end{array}$ & \multirow{2}{*}{ T Sig. } \\
\cline { 2 - 5 } & \multicolumn{2}{|c|}{ B } & Std. Error & Beta & \\
\hline \multirow{2}{*}{1 (Constant) } & $-1,015$ & 5,788 & & -175 &, 862 \\
$\begin{array}{c}\text { Kemajuan } \\
\text { teknologi } \\
\text { internet (X) }\end{array}$ & 1,532 & 146 &, 910 & 10,525 &, 000 \\
\hline
\end{tabular}

Sumber: Olahan data primer

diatas $\begin{gathered}\text { Berdasarkan hasil uji t pada tabel } \\ \text { dapat }\end{gathered}$ $t_{\text {hitung }}>t_{\text {tabel }}$ yakni sebesar10,525> 1,713 dan dengan signifikansi sebesar $0,000<\alpha(0,05)$, poin menunjukkan bahwa ada pengaruh cukup besar signifikansi antarakemajuan teknologi internetterhadap rendahnya minat belajar siswa secara positif dapat diterima.

Analisis determinasi $\mathrm{R}$ digunakan untuk mengetahui seberapa besar persentase sumbangan pengaruh variabel kemajuan teknologi internet secara serentak terhadap variabel rendahnya minat belajar siswa. Dapat dilihat tabel 5 dibawah ini:

Tabel5. Hasil Koefisien Determinasi ( $\square^{\square}$ )

Model Summary

\begin{tabular}{|l|r|r|r|r|}
\hline Model & \multicolumn{1}{|c|}{ R } & R Square & Adjusted R Square & $\begin{array}{r}\text { Std. Error of } \\
\text { the Estimate }\end{array}$ \\
\hline 1 &, $910^{\mathrm{a}}$ &, 828 &, 821 & 2,27279 \\
\hline
\end{tabular}

Sumber: Olahan data primer

\section{Berdasarkan hasil perhitungan} analisis regresi linear sederhana
menunjukkan bahwa pengaruhkemajuan teknologi internet terhadaprendahnya minat belajar siswa SMP Negeri 4 Ruteng Manggarai Barat dilihat dari nilai koefisien determinasi ( $\mathrm{R}^{\square}$ ) padaAdjusted $R$ Square yaitu sebesar 0,821 atau 82,1 persen.Berdasarkan hasil penelitian ini bahwa kemajuan teknologi internet berpengaruh terhadap rendahnya minat belajar siswa SMP Negeri 4 Ruteng Manggarai Barat dapat dibuktikan dengan hasil perhitungan bahwa nilai $t_{\text {tabel }}$ yaitu 1,713 dan sumbangan efektif sebesar 82,1 persen.

\section{KESIMPULAN DAN SARAN \\ Kesimpulan}

Berdasarkan hasil pembahasan penelitian tentang pengaruh kemajuan teknologi internet terhadap rendahnya minat belajar siswa SMP Negeri 4 Ruteng, maka dapat disimpulkan bahwa Berdasarkan hasil uji $\mathrm{t}$ pada tabel diatas dapat dijelaskan bahwa $t_{\text {hitung }}>t_{\text {tabel }}$ yakni sebesar10,525>1,713 dan dengan signifikansi sebesar $0,000<\alpha(0,05)$, poin menunjukkan bahwa ada pengaruh cukup besar signifikansi antarakemajuan teknologi internetterhadap rendahnya minat belajar siswa secara positif artinya disini terlihat bahwa semakin majunya teknologi internet maka semakin rendah minat belajar siswa kelas VIII SMP Negeri 4 Ruteng Manggarai Barat.

\section{Saran}

Berdasarkan kesimpulan yang telah dipaparkan, maka saran dalam penelitian ini adalah sebagai berikut:

a) Guru mengawasi secara sungguhsungguh dalam penggunaan teknologi internet dan terus berusaha untuk meningkatkan mianat belajar siswa

b) Bagi peserta didikterus belajar teknologi internet karena sebagai subjek milenial di era industri 4.0 


\section{DAFTAR PUSTAKA}

Castells, Manuel (2011).Communication Power, Oxford University Press, USA

Devi, Arisanti, Subhan (2018). Pengaruh

Penggunaan Media Internet

Terhadap Minat Belajar Siswa

Muslim Di SMP Kota Pekanbaru.

Jurnal Al-Thariqah.

Muhamad, Ngafifi (2014). Kemajuan

Teknologi Dan Pola Hidup Manusia

Dalam Perspektif Sosial

Budaya.Jurnal pembangunan pendidikan.

Muhamad Ngafifi (2014). Kemajuan

Teknologi Dan Pola Hidup Manusia

Dalam Perspektif Sosial

Budaya.Jurnal pembangunan

pendidikan. 2

Miskahudin (2017) Pengaruh Internet

Terhadap Penurunan Minat Belajar

Mahasiswa.Jurnal mudarrisuna.

Miarso, Yusufhadi, (2004). Menyemai

Benih Teknologi Pendidikan,

prenadamedia group, Jakarta

Rusno (2010).Pengaruh Penggunaan

Internet Sebagai Salah Satu Sumber

Belajar Terhadap Prestasi

Mahasiswa Pendidikan Ekonomi

Universitas Kanjuruhan

Malang.Jurnal Ekonomi

Modernisasi.

Ronald, Jimi (2016)Pengaruh Media

Pembelajaran Power Point

Terhadap Hasil Belajar Materi

Hukum Perusahaan Pada

Mahasiswa 2014 Sesi F Pendidikan

Ekonomi STKIP PGRI SUMBAR.
Jurnal Of Economic and Economic

Education vol.5 no.1

Sugiyono, (2010). Metode Pnelitian

Pendidikan Pendekatan Kuantitatif,

Kualitatif dan $R \& D$. Alfabeta,

Bandung.

Zakaria, Rokhman, (2016) Pengaruh

Motivasi Dan Penggunaan Internet Terhadap Prestasi Belajar Siswa

Dalam Pembelajaran Sejarah Di

MAN 2 Yogyakarta Tahun Ajaran

2015/2016. Universitas negeri

Yogyakarta

Soetam Rizky Wicaksono, (2019), Jaringan computer konsep dan studi kasus, Seribu Bintang, Malang Jawa Timur. 